\title{
Neuroanatomy Predicts Individual Risk Attitudes
}

\author{
Sharon Gilaie-Dotan, ${ }^{1 \star}$ Agnieszka Tymula, ${ }^{2, *}$ Nicole Cooper, ${ }^{3}$ Joseph W. Kable, ${ }^{3}$ Paul W. Glimcher, ${ }^{4}$ and Ifat Levy ${ }^{5}$ \\ ${ }^{1}$ Institute of Cognitive Neuroscience, University College London, London WC1N 3AR, United Kingdom, ${ }^{2}$ School of Economics, University of Sydney, \\ Sydney, New South Wales 2006, Australia, ${ }^{3}$ Department of Psychology, University of Pennsylvania, Philadelphia, Pennsylvania $19104,{ }^{4}$ Center for Neural \\ Science, New York University, New York, New York 10003, and ${ }^{5}$ Section of Comparative Medicine and Department of Neurobiology, Yale School of \\ Medicine, New Haven, Connecticut 06520
}

Over the course of the last decade a multitude of studies have investigated the relationship between neural activations and individual human decision-making. Here we asked whether the anatomical features of individual human brains could be used to predict the fundamental preferences of human choosers. To that end, we quantified the risk attitudes of human decision-makers using standard economic tools and quantified the gray matter cortical volume in all brain areas using standard neurobiological tools. Our whole-brain analysis revealed that the gray matter volume of a region in the right posterior parietal cortex was significantly predictive of individual risk attitudes. Participants with higher gray matter volume in this region exhibited less risk aversion. To test the robustness of this finding we examined a second group of participants and used econometric tools to test the ex ante hypothesis that gray matter volume in this area predicts individual risk attitudes. Our finding was confirmed in this second group. Our results, while being silent about causal relationships, identify what might be considered the first stable biomarker for financial risk-attitude. If these results, gathered in a population of midlife northeast American adults, hold in the general population, they will provide constraints on the possible neural mechanisms underlying risk attitudes. The results will also provide a simple measurement of risk attitudes that could be easily extracted from abundance of existing medical brain scans, and could potentially provide a characteristic distribution of these attitudes for policy makers.

Key words: decision making; parietal cortex; risk aversion; structural MRI; subjective value

\section{Introduction}

Individuals vary greatly in the amount of risk they tolerate. While some avoid taking risks at any cost, others put their wealth, health, or safety at risk. Economists and psychologists have long viewed individual risk attitudes as a fundamental trait, often called risk preference (Bernoulli, 1954; Von Neumann and Morgenstern, 1944; Kahneman and Tversky, 1979; Weber et al., 2002). Yet, there is currently no stable and easy-to-extract biomarker for characterizing this fundamental trait at the individual level.

The last few years have, however, seen a surge of functional neuroimaging studies successfully linking neural activity in several brain areas with participant-specific decision-making under risk in a variety of circumstances (Kuhnen and Knutson, 2005; Huettel et al., 2006; Preuschoff et al., 2006; Levy et al., 2010). Activation levels in a number of these regions have been shown to reflect the idiosyncratic valuations individuals place on a host of

\footnotetext{
Received April 18, 2014; revised July 9, 2014; accepted July 28, 2014.

Author contributions:S.G.-D., A.T., J.W.K.,P.W.G., and I.L. designed research; A.T. and N.S.C. performed research; S.G.-D. and A.T. analyzed data; S.G.-D., A.T., J.W.K., P.W.G., and I.L. wrote the paper.

This work was funded by NIH/NIA Grant R01AG033406 to I.L. and P.W.G., and NIH/NIDA Grant R01DA029149 to J.W.K. N.C. was supported by T32-MH017168. We thank Ari Meilich, Stav Atir, Jessica Bodie, Nico Harbig, Joe McGuire, Dahlia Mukherjee, and Shikha Saxena for assisting with data collection.

The authors declare no competing financial interests.

*S.G.-D. and A.T. contributed equally to this work.

Correspondence should be addressed to Dr Ifat Levy, Section of Comparative Medicine, Yale School of Medicine, PO Box 208016, New Haven, CT 06520. E-mail: Ifat.levy@yale.edu.

DOI:10.1523/JNEUROSCI.1600-14.2014

Copyright $\odot 2014$ the authors $\quad 0270-6474 / 14 / 3412394-08 \$ 15.00 / 0$
}

rewards (Bartra et al., 2013), including immediate and delayed monetary rewards (Kable and Glimcher, 2007), food and drink rewards (O'Doherty et al., 2002; Plassmann et al., 2007; Chib et al., 2009; Hare et al., 2009; Levy and Glimcher, 2011), and social rewards (Izuma et al., 2008). Indeed, the activity patterns in these areas can be used to predict much about an individual's preferences. Despite these advances, it remains unclear whether such preferences can be reliably inferred from more basic structural measurements of the human brain, neuroanatomical images of the kind gathered in standard medical exams, that can be collected very quickly, at low cost, and do not require participants to reveal their preferences behaviorally.

Individual differences in diverse cognitive and perceptual functions can be reliably inferred from neuroanatomical structure (Maguire et al., 2000; Gaser and Schlaug, 2003; Gilaie-Dotan et al., 2011, 2013; Kanai and Rees, 2011). Here we investigated whether neuroanatomical traits of passive participants could be similarly used to predict participant-specific behavioral preferences. To accomplish this, we obtained from our participants structural brain images and characterized their financial risk attitudes using well validated and incentive-compatible techniques from experimental economics. We found that gray matter (GM) volume in a region of the posterior parietal cortex, an area long associated with decision-making in animals and humans (Platt and Glimcher, 1999; Sugrue et al., 2004; Huettel et al., 2006; Louie and Glimcher, 2010; Clithero and Rangel, 2013), strongly predicted risk preferences, a result which was confirmed in a second independent group of participants. Individuals with more GM volume in this area have greater tolerance for financial risk. Our 
A

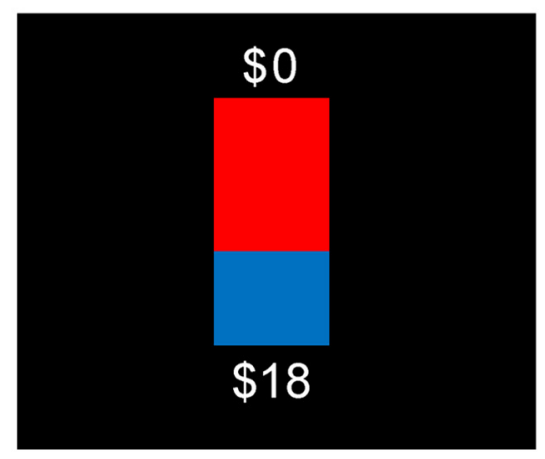

B

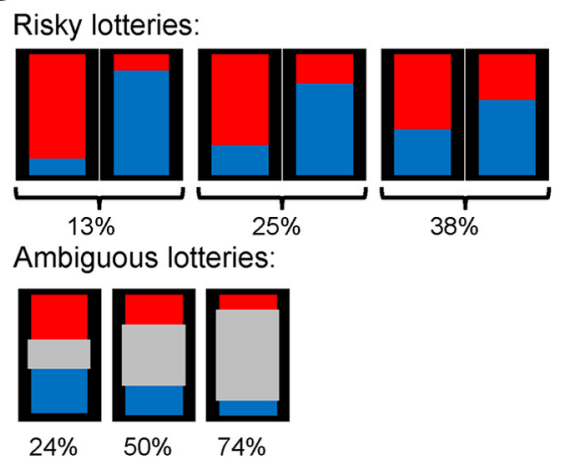

Figure 1. Study 1: experimental design. $\boldsymbol{A}$, An example of a choice trial. The participant can either choose the option on the screen: $38 \%$ chance of $\$ 18$, or the reference lottery that offers $\$ 5$ with $50 \%$ probability. The reference lottery was available in each trial. The on-screen option changed from trial-to-trial. There were five reward levels $(\$ 5, \$ 9.5, \$ 18, \$ 34$, and $\$ 65)$, each fully crossed with three winning probabilities $(13,25$, and $38 \% ; \boldsymbol{B}$, top) as well as three levels of ambiguity around the winning probability $(24,50$, and $74 \% ; \boldsymbol{B}$, bottom).

finding suggests the existence of a simple biomarker for risk attitude, at least in the midlife population we examined in the northeastern United States. This result may place important constraints on the neural mechanisms implementing the algorithms by which we express our preferences. If generalized to other groups, this finding will also imply that individual risk attitudes could, at least to some extent, be measured in many existing medical brain scans, potentially offering a tool for policy makers seeking to characterize the risk attitudes of populations.

\section{Materials and Methods \\ Study 1}

Participant information

Twenty-eight healthy individuals (15 women), aged $25 \pm 6$ (SD) participated in the study. They were recruited using flyers posted in the university buildings. The data were collected at New York University. Participants had normal or corrected-to-normal vision. All participants provided written informed consent and the research was approved by the University Committee on Activities Involving Human Subjects at New York University. The behavioral task that was used to characterize individual risk attitudes was performed by all participants after their MRI anatomical scan was completed. Twenty-one of the participants performed the behavioral task inside of the scanner, during a functional scan (results from the functional scan were reported previously; Levy et al., 2010). Because we decided to investigate the relationship between economic preferences and brain structure only after the fMRI study was completed (Levy et al., 2010), and because neuroanatomical statistics are more reliable at $\sim n=30$, to reach an appropriate sample size for the structural study we invited seven additional participants, and they performed the behavioral task outside the scanner, after their MRI anatomical scan. It is important to emphasize that post hoc analysis based on the original group of $n=21$ (Levy et al., 2010) reached whole-brain significant neuroanatomical results in precisely the same anatomical location as the extended $(n=28)$ group.

\section{Experimental design}

Each study participant faced a series of choices, each between two different monetary options. One option, the reference lottery, was a $50 \%$ chance of winning $\$ 5$ (or $\$ 0$ otherwise) and was available in every round. The other option, presented to the participants on the screen (Fig. $1 \mathrm{~A}$ shows an example trial), would vary from trial to trial in terms of the reward magnitude ( $\$ 5, \$ 9.5, \$ 18, \$ 34$ and $\$ 65)$, and either the probability of obtaining it $(13,25$, and $38 \%)$ or the ambiguity around this probability $(24,50$, and $74 \%)$. On each trial, the amount was varied slightly $( \pm \$ 0.1)$ to maintain participant attention. The probability of winning was communicated via visual displays of "bags" filled with blue and red poker chips, where the relationship of red-to-blue poker chips indicated the probability of winning (Fig. $1 B$ shows all probability stimuli used in the experiment). In what follows we refer to risk as being higher[lower] when the winning probability for the same outcome is lower[higher]. In half of the trials, blue was the winning color, in the other half red was the winning color. Overall that yields a total of 60 unique trial types [ 5 rewards $\times(3$ risk levels +3 ambiguity levels) $\times 2$ color combinations]. Each trial type was repeated three times. Trials were presented in a randomized order. Each participant faced the same set of 180 choices. Choices were presented using E-Prime (Psychology Software Tools), and participants made their choices using either a response box or a keyboard. At the end of the experiment, each participant rolled a die to select three trials. The choices that this participant made on these three trials would determine her payment, in addition to a flat-fee for participation.

\section{Model-based estimation of risk attitudes}

We estimated individual risk attitudes using the following form of an expected utility function for option $i$ (which under these conditions is identical to the form of the value function in prospect theory; Kahneman and Tversky, 1979):

$$
E U_{i}=\left(p-\beta \times \frac{A}{2}\right) \times x^{\alpha}
$$

where $x$ is the reward size, $p$ is the probability of winning this reward, and $A$ is the ambiguity about that probability (Gilboa and Schmeidler, 1989). The exponent, $\alpha$, is the estimated risk attitude; $\alpha<1(>1)$ indicates risk aversion (seeking); $\alpha=1$ indicates risk neutrality (i.e., the participant is indifferent between two options that have the same "expected value" but involve different levels of risk). $\beta$ is the estimate of the individual ambiguity attitude. For each individual, her observed choices were fit using a maximum likelihood procedure, fitting the likelihood for choosing option $i$ as follows:

$$
\operatorname{Pr}(\text { Chose_i })=\frac{1}{1+\exp \left(-\left(E U_{i}-E U_{j}\right) / \sigma\right)}
$$

where $E U_{i}$ and $E U_{j}$ are the expected utilities of option $i$ and option $j$ respectively, and $\sigma$ determines the slope of the choice function. This estimation procedure yielded risk and ambiguity estimates for each of the study participants which were later used in the voxel-based morphomentry (VBM) analysis to look for regions of the brain, in which GM volume would correlate with individual risk or ambiguity attitudes.

\section{Model-free risk estimates}

To make sure that our results were not specific to the econometric assumptions underlying the estimation process (as determined by expected utility theory or prospect theory), we validated our findings with a completely model-free estimate of risk attitudes. In our experimental design, the reference lottery, the option that was available in each trial, had the highest possible probability of winning and the lowest variance and thus involved the lowest level of risk out of all lotteries included in the experiment. We would thus expect more risk-averse participants to choose the reference lottery more often and more risk-tolerant participants to choose the reference lottery less often. Therefore, for each individual we characterized her risk attitude by calculating the proportion of times she did not select the reference lottery. The higher this fraction, the more risk tolerant the individual was. Ambiguous trials (trials where there was some ambiguity regarding the probability of winning) were not included in this analysis.

\section{MRI structural acquisition}

Anatomical images were collected using a 3T Siemens Allegra scanner equipped with a custom RF coil (NM-011 transmit head coil, NOVA 
Medical). High-resolution T1-weighted anatomical images $(1 \times 1 \times 1$ $\mathrm{mm}^{3}$ ) were acquired with an MPRAGE pulse sequence (TI $=900 \mathrm{~ms}$, sagittal slices, $256 \times 256$ matrix).

\section{VBM analysis}

All VBM analyses were performed using SPM8 (http://www.fil.ion. ucl.ac.uk/spm).

Preprocessing. For each participant the structural MR images were first segmented to GM and white matter (WM) using the SPM8 segmentation tools. Afterward, we performed intersubject registration of the GM images via the Diffeomorphic Anatomical Registration through Exponentiated Lie Algebra (DARTEL) in SPM8 (Ashburner and Friston, 2000; Ashburner, 2007). In this coregistration preprocessing, the local GM volumes were conserved by modulating the image intensity of each voxel by the Jacobian determinants of the deformation fields computed by DARTEL. The registered images were then smoothed with a Gaussian kernel (FWHM $=8 \mathrm{~mm}$ ) and transformed to MNI stereotactic space using affine and nonlinear spatial normalization for multiple regression analysis.

Second level modeling and contrasts. Multiple regression analyses were then performed. The first multiple regression analysis aimed to examine neuroanatomical correlates of risk attitudes based on the econometric model-based estimations (see Model-based estimation of risk attitudes, above). The covariate of interest included in this model was the level of risk aversion as assessed by $\alpha$. The age and gender of the participants and global GM volume (following ANCOVA normalization) were included in the design matrix as covariates of no interest, and were thus regressed out. $F$ contrasts were applied first with $p<0.001$ uncorrected as the criterion to detect voxels with significant correlation to individual's risk attitudes $(\alpha)$. Whole-brain correction procedures were then applied as described in the next paragraph. The second multiple regression analysis aimed to examine the neuroanatomical correlates of risk attitudes based on the model-free estimations (frequencies of the riskier lottery choices, see Model-free risk estimates, above). This analysis was precisely the same as the first analysis, except that the covariate of interest was the model-free risk attitudes instead of $\alpha$. We also ran a third similar analysis where the covariate of interest was the ambiguity attitudes $(\beta)$. Finally, we ran multiple regression analysis examining risk and ambiguity jointly in the same model (as two separate covariates of interest).

Whole-brain correction. Because structural images display local variation in smoothness, standard applications of cluster-based random field theory are inappropriate (Hayasaka et al., 2004). Therefore nonstationary whole-brain cluster-level correction was applied using the "NonStationary Cluster Extent Correction for SPM" toolbox (http://fmri. wfubmc.edu/cms/NS-General; Hayasaka et al., 2004). We report only the results of clusters that survived this nonstationary correction for multiple comparisons across the whole brain at a threshold of $p$ (corrected) $<0.05$. No cluster-size cutoff was applied in any of the analyses.

To verify that the observed correlations in Study 1 were not driven by outliers in the data, average GM densities were extracted from each significant cluster using the MarsBar toolbox (http://marsbar.sourceforge. net; M.Brett, J. Anton, R. Valabregue, and J. Poline. Human Brain Mapping conference, Japan, 2002) and plotted against individual performance (Fig. 2). Note that these plots are for visualization purposes only and are not to be used for statistical inference to avoid circular reasoning (Kriegeskorte et al., 2009).

\section{Study 2}

\section{Participant information}

Thirty-three healthy individuals (20 women), aged $21.34 \pm 2.35$ (SD) from the University of Pennsylvania community participated in the study and were included in this dataset. Participants were recruited primarily through university-run websites dedicated to experimental posting and scheduling. Participants had normal or corrected-tonormal vision. All participants provided written informed consent and the research was approved by the Institutional Review Board of the University of Pennsylvania. Participants performed the behavioral task outside the scanner on a different day than when they were scanned.
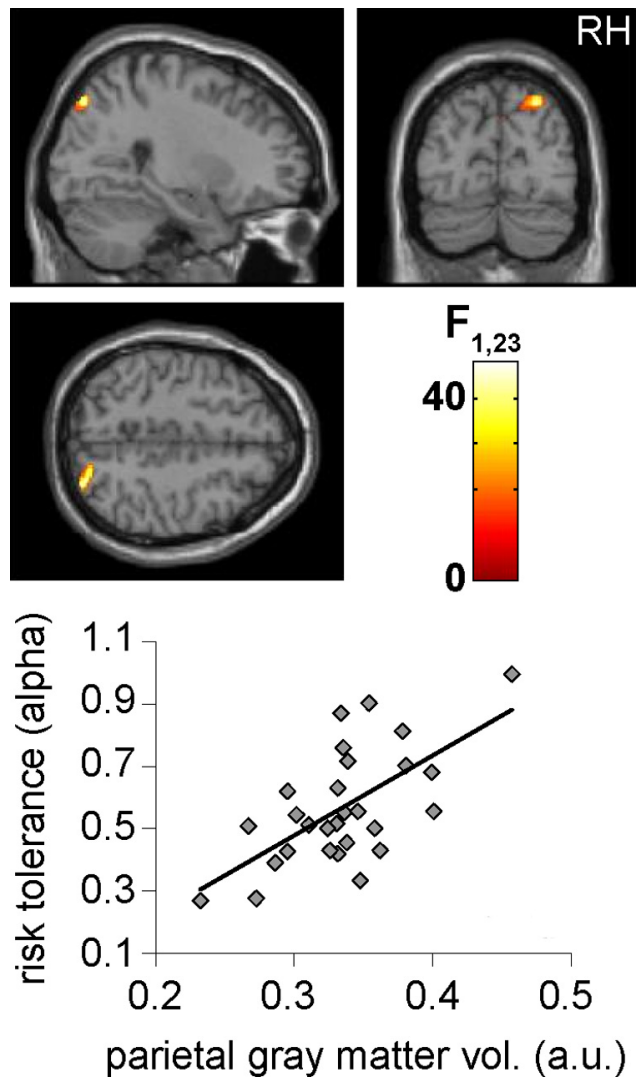

Figure 2. Study 1: whole-brain model-based analysis. Top, The GM volume of a region in the right PPC (MNI coordinates $27,-78,48 ; p$ (corrected) $=0.001,1232 \mathrm{~mm}^{3}$ ) was significantly correlated with individual risk attitudes, estimated as the curvature of the utility function, as revealed by a voxel-based morphometry analysis (age, gender, and global volume are controlled for). Bottom, To demonstrate that the observed correlations were not driven by outliers, for each individual, GM volume of the PPC cluster (top) is plotted on the $x$-axis against risk attitude on the $y$-axis. Note that this should not be used for inference as it is not independent of the whole-brain analysis and is presented for visualization purposes only. No other regions were found to be correlated with risk attitudes. RH, Right hemisphere.

For most of the participants in Study 2 we were able to collect the following demographics information. Twenty-seven of the participants were students, and five others were non-students and employed. Eighteen of the participants had finished high school, 13 had a bachelor's degree, and two had a master's degree. The average "new" SAT score of 16 participants was $2092.5 \pm 147.6$ (SD), out of 2400; the average "old" SAT score of additional 10 participants was $1381 \pm 151.3$ (SD), out of 1600 . Twenty-five were native English speakers. Participants' annual income ranged between 0 and 37,600 USD [mean $7610 \pm 11,152$ (SD)]. They grew up in families of two to seven members [mean of $4.19 \pm 1.47$ (SD)]. None of the participants had children; all of them were single except for two, who were living with someone, and two that were married. They reported whether at least one of their parents had high school education $(n=5)$, college education $(n=3)$, bachelors $(n=4)$, masters $(n=15)$, or doctoral degree $(n=5)$. Twenty-seven participants provided an estimate for their parents' income ranging from 2000 to 800,000 USD (mean $117,296 \pm 160,072$ ). Twenty-eight (4) were right (left) handed.

\section{Experimental design}

Each study participant made 60 nonrepeating choices between a smaller amount of money for certain, versus a $50 \%$ chance of winning a larger amount or a $50 \%$ chance of winning nothing. The smaller amounts varied from $\$ 1$ to $\$ 63$, and the larger amounts from $\$ 10$ to $\$ 100$. Choices were presented using E-Prime (Psychology Software Tools), and participants made their choices using a keyboard.

The risk task was completed as part of a battery of other decisionmaking tasks. In addition to a flat-fee for participation, participants were 
Table 1. Maximum likelihood estimates of risk attitude determinants in Study 2 based on the parietal ROI

\begin{tabular}{|c|c|c|c|c|c|c|}
\hline Sphere radius (mm) & 5 & 10 & 15 & 20 & 25 & 30 \\
\hline \multicolumn{7}{|l|}{ Risk tolerance $(\boldsymbol{\alpha})$} \\
\hline —Parietal volume & $\begin{array}{c}0.694 \\
(0.711)\end{array}$ & $\begin{array}{c}1.114 \\
(0.714)\end{array}$ & $\begin{array}{c}1.499^{*} \\
(0.734)\end{array}$ & $\begin{array}{c}1.781^{*} \\
(0.850)\end{array}$ & $\begin{array}{c}1.781 \\
(0.976)\end{array}$ & $\begin{array}{c}1.806 \\
(1.062)\end{array}$ \\
\hline 一Age & $\begin{array}{c}-0.003 \\
(0.008)\end{array}$ & $\begin{array}{c}-0.003 \\
(0.008)\end{array}$ & $\begin{array}{c}-0.004 \\
(0.008)\end{array}$ & $\begin{array}{c}-0.005 \\
(0.008)\end{array}$ & $\begin{array}{r}-0.005 \\
(0.009)\end{array}$ & $\begin{array}{r}-0.003 \\
(0.009)\end{array}$ \\
\hline —Female & $\begin{array}{r}-0.112^{*} \\
(0.053)\end{array}$ & $\begin{array}{c}-0.121^{* *} \\
(0.044)\end{array}$ & $\begin{array}{c}-0.126^{* * *} \\
(0.038)\end{array}$ & $\begin{array}{c}-0.119^{* *} \\
(0.041)\end{array}$ & $\begin{array}{r}-0.112^{*} \\
(0.049)\end{array}$ & $\begin{array}{r}-0.114^{*} \\
(0.049)\end{array}$ \\
\hline _Global volume & $\begin{array}{c}0.100 \\
(1.138)\end{array}$ & $\begin{array}{c}-0.399 \\
(1.244)\end{array}$ & $\begin{array}{c}-0.933 \\
(1.306)\end{array}$ & $\begin{array}{c}-1.304 \\
(1.478)\end{array}$ & $\begin{array}{c}-1.399 \\
(1.661)\end{array}$ & $\begin{array}{r}-1.561 \\
(1.752)\end{array}$ \\
\hline —Constant & $\begin{array}{c}0.602^{*} \\
(0.283)\end{array}$ & $\begin{array}{c}0.597^{*} \\
(0.301)\end{array}$ & $\begin{array}{c}0.611^{*} \\
(0.301)\end{array}$ & $\begin{array}{c}0.617^{*} \\
(0.308)\end{array}$ & $\begin{array}{c}0.635^{*} \\
(0.320)\end{array}$ & $\begin{array}{c}0.652^{*} \\
(0.318)\end{array}$ \\
\hline Noise $(\sigma)$ & & & & & & \\
\hline —Constant & $\begin{array}{l}1.062^{* * *} \\
(0.149)\end{array}$ & $\begin{array}{l}1.052^{* * *} \\
(0.147)\end{array}$ & $\begin{array}{l}1.042^{* * *} \\
(0.147)\end{array}$ & $\begin{array}{l}1.043^{* * *} \\
(0.149)\end{array}$ & $\begin{array}{l}1.053^{* * *} \\
(0.149)\end{array}$ & $\begin{array}{l}1.056^{* * *} \\
(0.149)\end{array}$ \\
\hline
\end{tabular}

Risk attitudes were regressed on parietal volume, age, female, and global volume for each size of the sampled ROls. Each column shows the estimated coefficients (SEs in parenthesis below each estimate) as a function of sphere size (5-30 $\mathrm{mm}$ radius). SEs were clustered on participant. Significant results are indicated by asterisks; $N$ (total number of observations) $=1974$. Note that parietal GM volume coefficients of 15 - and 20 -mm-radii spheres were significant in explaining individual differences in risk attitudes (Fig. $4 A, C$ ).

${ }^{*} p<0.05,{ }^{* *} p<0.01,{ }^{* * *} p<0.001$.

paid for one, randomly selected decision that they made during the experimental session.

\section{MRI structural acquisition}

Anatomical images were collected using a 3T Siemens Trio scanner equipped with a 32-channel head coil. High-resolution T1-weighted anatomical images $\left(0.9375 \times 0.9375 \times 1.000 \mathrm{~mm}^{3}\right)$ were acquired using an MPRAGE pulse sequence $(\mathrm{TI}=1100 \mathrm{~ms}$, axial slices, $192 \times 256$ matrix $)$.

\section{VBM analysis}

All VBM analyses were performed using SPM8 (http://www.fil.ion. ucl.ac.uk/spm).

Preprocessing. All the preprocessing stages followed precisely the same steps as the ones described for Study 1.

Region-of-interest GM volume sampling. To parametrically sample the GM volume around the parietal focus we found in Study 1, we created spheres of growing radii around the peak of that focus (centered at MNI coordinates $27,-78,48$ ) with $5,10,15,20,25$, and $30 \mathrm{~mm}$ radii, using Marsbar toolbox for SPM. To ensure that only within-brain matter will be sampled, and because some of the bigger spheres included out-ofbrain volume, all out-of-brain volume was excluded. The same procedure was applied to the control region in M1/S1 around MNI coordinates $20,-35,72$. The SPM Marsbar toolbox was then used to sample the GM volume of all participants of Study 2 from each of these predefined regions-of-interest (ROIs).

\section{Model-based estimation of risk attitudes}

To determine whether risk attitudes of participants from Study 2 were correlated with the GM volume of the posterior parietal cortex (PPC) region, we checked whether this brain measurement can be used to account for the participant-to-participant variability in risk attitudes (around this sample mean) that we observed in this second study. Using a maximum likelihood procedure, we estimated a structural model of the choice process of our study participants, in which we allowed risk preference parameter to vary with age, gender, and GM volume. We modeled the expected utility of a given lottery as follows:

$$
E U(x, p)=p \times x^{\alpha}
$$

where $x$ is the reward size, $p$ is the probability of winning this reward and the exponent, $\alpha$, is the estimated risk attitude (see details of Study 1). In an estimation process designed to test the hypothesis that the GM density of each participant's right PPC accounts for how that participant's risk attitude deviates from the population mean risk attitude, we allowed the risk parameter, $\alpha$, to relate to GM volume in the following way:

$\alpha=\gamma_{1} \times$ graymatter $+\gamma_{2} \times$ age $+\gamma_{3} \times$ female $+\gamma_{4}$ where graymatter is the GM volume of the right PPC in our ROI, age indicates participant's age, female is an indicator variable equal to 1 if the participant is female and 0 otherwise, globalvolume is the global GM volume, and $\gamma_{0}$ is a constant.

We then fit all of the choices obtained from all the participants at the same time, using a logistic choice function and a maximum likelihood procedure. SEs were clustered on the participant to account for the fact that the observations coming from one participant may be correlated and thus to make sure our results are not exaggerated. Using this standard econometric approach (Harrison and Rutstrom, 2008), if GM volume in each participant accounts for how that participant's choices vary (with regard to $\alpha$ ) from the population mean, then the coefficient, $\gamma_{1}$, should be reported as significant by our analysis. The advantage of this traditional econometric approach over other approaches, which may be more familiar to neurobiologists, is that it explicitly allows us to account for within and between participant variabilities in an assumption-free and statistically rigorous manner.

We performed this analysis using GM volume of Study 2 participants from both the right parietal cortex, which was identified in Study 1 as the $\mathrm{ROI}$, and a region in the vicinity of primary motor/primary somatosensory areas (M1/S1) as a control region. We found that the GM volume of the parietal region significantly contributes to explaining variation in individual risk attitudes, whereas the GM volume of the control region, $\mathrm{M} 1 / \mathrm{S} 1$, does not. The analysis results are presented in Figure 4, and Tables 1 and 2.

\section{Results}

In Study 1 we used a standard experimental economics technique (Levy et al., 2012), that was validated in several previous studies (Levy et al., 2010; Tymula et al., 2012, 2013), to measure risk and ambiguity attitudes (Fig. $1 A$ shows an example of a typical choice trial; see Materials and Methods) and to examine how they are reflected in neuroanatomical structure.

The estimated individual attitudes for risk and ambiguity (Kahneman and Tversky, 1979; Gilboa and Schmeidler, 1989; see Materials and Methods) were then used in a VBM analysis (Ashburner and Friston, 2000; see Materials and Methods). We found that the GM volume of a cluster in the right posterior parietal cortex, in the vicinity of the lateral intraparietal sulcus (IPS), was significantly correlated with risk attitudes (MNI coordinates 27, $-78,48,1232 \mathrm{~mm}^{3}, p$ (corrected) $=0.001, F_{(1,23)}=48.23, Z=$ 4.91 ), such that more GM volume in that region corresponded to more risk tolerance (Fig. 2). Gray matter volume in no other region was significantly correlated with risk tolerance using this analytic technique. We did not find any brain region whose GM 
Table 2. Maximum likelihood estimates of risk attitude determinants in Study 2 based on the control region

\begin{tabular}{|c|c|c|c|c|c|c|}
\hline Sphere radius (mm) & 5 & 10 & 15 & 20 & 25 & 30 \\
\hline \multicolumn{7}{|l|}{ Risk tolerance $(\alpha)$} \\
\hline —M1/S1 volume & $\begin{array}{c}0.513 \\
(0.395)\end{array}$ & $\begin{array}{c}0.729 \\
(0.538)\end{array}$ & $\begin{array}{c}1.008 \\
(0.745)\end{array}$ & $\begin{array}{c}1.313 \\
(1.085)\end{array}$ & $\begin{array}{c}1.357 \\
(1.598)\end{array}$ & $\begin{array}{c}1.081 \\
(1.957)\end{array}$ \\
\hline —Age & $\begin{array}{c}-0.001 \\
(0.008)\end{array}$ & $\begin{array}{c}-0.001 \\
(0.008)\end{array}$ & $\begin{array}{c}-0.001 \\
(0.008)\end{array}$ & $\begin{array}{c}-0.001 \\
(0.008)\end{array}$ & $\begin{array}{c}-0.002 \\
(0.008)\end{array}$ & $\begin{array}{c}-0.003 \\
(0.008)\end{array}$ \\
\hline —Female & $\begin{array}{c}-0.142^{* * *} \\
(0.036)\end{array}$ & $\begin{array}{c}-0.149^{* * *} \\
(0.034)\end{array}$ & $\begin{array}{c}-0.153^{* * *} \\
(0.035)\end{array}$ & $\begin{array}{c}-0.152^{* * *} \\
(0.036)\end{array}$ & $\begin{array}{c}-0.145^{* * *} \\
(0.039)\end{array}$ & $\begin{array}{c}-0.135^{* * *} \\
(0.040)\end{array}$ \\
\hline _Global volume & $\begin{array}{r}-0.033 \\
(0.896)\end{array}$ & $\begin{array}{c}-0.204 \\
(0.985)\end{array}$ & $\begin{array}{c}-0.517 \\
(1.199)\end{array}$ & $\begin{array}{c}-0.921 \\
(1.612)\end{array}$ & $\begin{array}{c}-1.028 \\
(2.241)\end{array}$ & $\begin{array}{c}-0.692 \\
(2.621)\end{array}$ \\
\hline —Constant & $\begin{array}{c}0.651^{*} \\
(0.259)\end{array}$ & $\begin{array}{c}0.650^{*} \\
(0.255)\end{array}$ & $\begin{array}{c}0.670^{* *} \\
(0.254)\end{array}$ & $\begin{array}{c}0.725^{* *} \\
(0.273)\end{array}$ & $\begin{array}{c}0.755^{*} \\
(0.314)\end{array}$ & $\begin{array}{c}0.721^{*} \\
(0.326)\end{array}$ \\
\hline Noise $(\sigma)$ & & & & & & \\
\hline —Constant & $\begin{array}{l}1.045^{* * *} \\
(0.149)\end{array}$ & $\begin{array}{l}1.041^{* * *} \\
(0.148)\end{array}$ & $\begin{array}{l}1.039^{* * *} \\
(0.148)\end{array}$ & $\begin{array}{l}1.043^{* * *} \\
(0.148)\end{array}$ & $\begin{array}{l}1.053^{* * *} \\
(0.148)\end{array}$ & $\begin{array}{l}1.060^{* * *} \\
(0.149)\end{array}$ \\
\hline
\end{tabular}

Risk attitudes were regressed on M1/S1 volume, age, female, and global volume for each size of the sampled Rol. Presentation conventions as in Table 1; $N=1974$. GM volume coefficients of the control region did not significantly explain individual differences in risk attitudes (Fig. $4 B, D$ ).

${ }^{*} p<0.05,{ }^{* *} p<0.01,{ }^{* *} p<0.001$.

volume significantly correlated with individual ambiguity attitudes, even at more lenient thresholds (whole-brain nonstationary corrected $p=0.05$, and single voxel noncorrected $p=0.05$ ), or when we examined ambiguity jointly with risk, which yielded the same results as when we examined them singly.

To further confirm the robustness of our finding, we wanted to make sure that the results did not depend on the specific modeling and econometric assumptions underlying our behavioral technique for estimating risk attitudes. We therefore repeated the VBM analysis (Study 1), but this time using a completely modelfree measure of risk attitude, where individual propensity to take risks is simply characterized by the number of times an individual chose the "riskier" of the two available lottery choices. Because in our design the reference lottery of $\$ 5$ at $50 \%$ chance of winning was the least "risky" lottery of the ones we examined (see Materials and Methods), we were able to quantify individual attitudes to risks by calculating the frequency of the on-screen, riskier lottery choices. By any method of estimating risk-aversion, a more risk-averse participant would be one who chose the reference lottery more often. A more risk-tolerant participant is one who would choose the on-screen, riskier lotteries more frequently. Formally, this approach thus yielded an ordinal ranking of risk-tolerance in our participants that did not depend on any cardinal assumptions (Tymula et al., 2013). VBM analysis based on these model-free risk-attitude estimates revealed a wholebrain corrected cluster $\left(472 \mathrm{~mm}^{3}\right.$ centered at MNI coordinates 27, -79, 48; Fig. 3) overlapping the cluster revealed by the modelbased analysis, whose GM volume was significantly correlated with individual risk attitudes [ $p$ (whole-brain nonstationary-corrected $\left.)=0.038, F_{(1,23)}=32.19, Z=4.29\right]$. Thus, the GM volume of the right parietal focus that was significantly correlated with the model-based risk estimates, was also significantly correlated with the model-free (ordinal) risk estimates (compare Figs. 2, 3). In addition, it should be noted that using the model-free risk estimate, we found another focus in the medial prefrontal cortex, whose GM volume was significantly predictive of risk attitudes $\left[p(\right.$ whole-brain nonstationary-corrected $)=0.032, F_{(1,23)}=$ 26.50, $Z=3.99$; the cluster of $1766 \mathrm{~mm}^{3}$ was centered at MNI coordinates $11,56,7]$.

To examine the reliability of the correlation between GM volume of the posterior parietal cortex and risk attitudes, we obtained an independent dataset (Study 2, $n=33$ ) that included structural MRI brain measurements and behavioral data from a
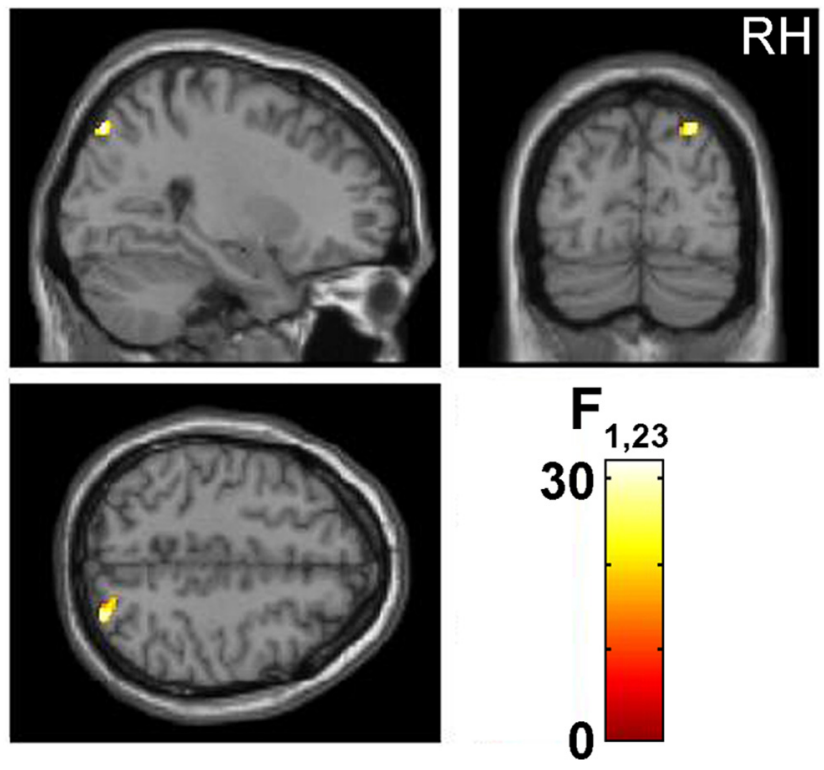

Figure 3. Study 1: whole-brain model-free analysis. The GM volume of the right posterior parietal cortex that was significantly correlated with risk attitudes as assessed by parametric analysis (presented in Fig. 2) was also significantly correlated with risk attitudes when assessed by a model-free analysis (i.e., proportion of riskier choices made by the participant). A cluster of $472 \mathrm{~mm}^{3}$ centered at MNI coordinates $27,-79,48$ was significantly correlated with the frequency of riskier choices [ $p$ (whole-brain nonstationary-corrected) $=0.038, F_{(1,23)}=32.19$, $Z=4.29]$. Right hemisphere presented on the right. Display conventions as in Figure 2.

similar risky decision task (see Materials and Methods, Study 2). For each individual in this new, independent, dataset we sampled the GM volume around the center of the parietal focus identified in Study 1 and examined how well it could predict behavioral variations in risk attitudes (see Materials and Methods). As Figure $4 A$ reveals, we again found a positive and significant relationship between parietal GM volume and risk attitudes, suggesting that this relationship is a robust phenomenon. The relationship between the sampled sphere size and the ability of the parietal GM volume to explain variation in risk attitude was quadratic, reaching peak significance for spheres of 15- and 20-mm-radii (Fig. 4A; Table 1), implying that our finding is restricted to this region and is not a whole-brain property. Figure $4 C$ graphically shows the relationship between each participant's risk attitude and her parietal GM volume. Moreover, the GM volume of the 


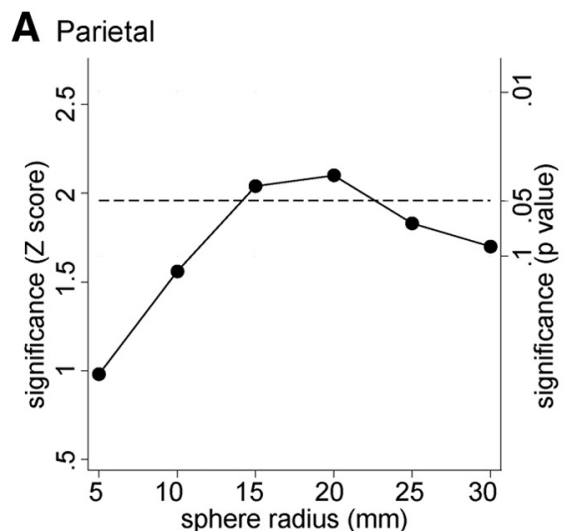

\section{B $\mathrm{M} 1 / \mathrm{S} 1$}

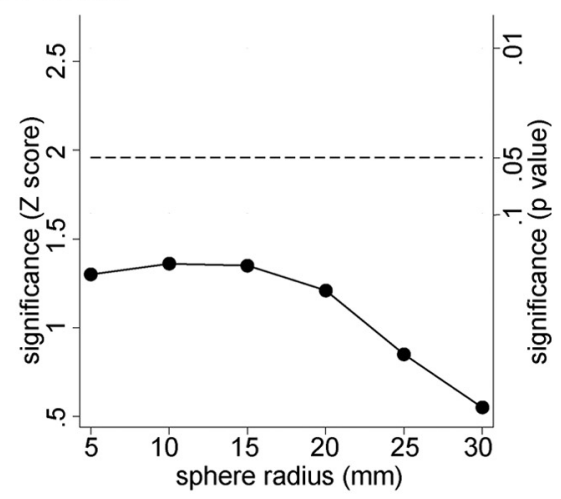

C Parietal

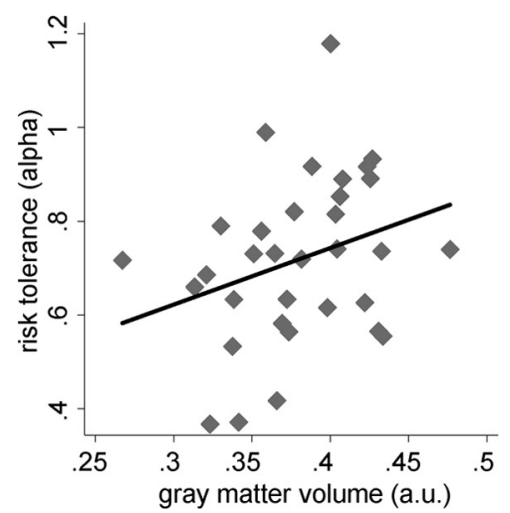

\section{D $\mathrm{M} 1 / \mathrm{S} 1$}

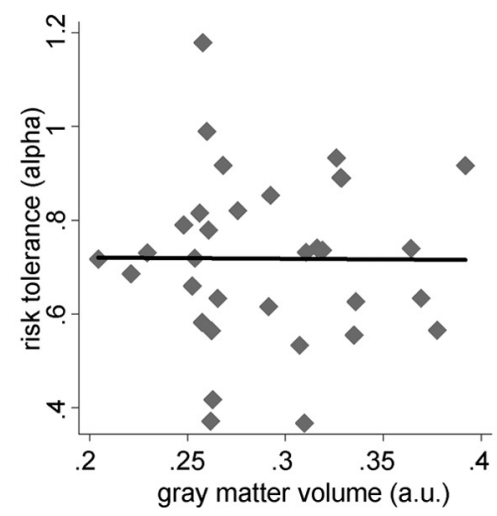

Figure 4. Study 2: ROI analysis. Significance of GM volume in explaining individual risk attitudes for: $\boldsymbol{A}$, parietal cortex (around $27,-78,48) ; \boldsymbol{B}$, a control region M1/S1 (around 20, -35, 72); age, gender, and global volume are controlled for. The $x$-axis represents the size (sphere radius around the peak) of the sampled brain region; $y$-axes indicate the significance level (Z-score on the left, $p$ value on the right) of the GM volume variable in explaining risk attitude (Tables 1, 2). Dashed line indicates $5 \%$ significance threshold ( $p=0.05$ ). Dots (below) above the dashed line indicate (in)significant results. $\boldsymbol{C}, \boldsymbol{D}$, Relationship between risk tolerance and GM volume in the $20 \mathrm{~mm}$ sphere of parietal cortex $(\boldsymbol{C})$ or control region M1/S1 (D). Risk tolerance $(\alpha)$ was estimated for each individual separately using the same procedure as in Study 1 (see Materials and Methods). Importantly, the risk estimates are based on individual's behavior only, and the GM volume was sampled independently using MarsBar toolbox for SPM.

control region in the vicinity of the primary-motor/primarysomatosensory cortex (M1/S1) did not successfully predict risk attitudes regardless of the sphere radius used (Fig. $4 B, D$; Table 2).

To test whether there were any additional effects in Study 2 that were not observed in Study 1, we followed the ROI-based analysis with a standard VBM whole-brain analysis. This analysis did not reveal any additional regions whose volume significantly correlated with risk attitudes. Summing up, our results indicate that the GM volume of the right posterior parietal cortex reliably predicts individual risk attitudes in two independent datasets.

\section{Discussion}

Although structural neuroanatomical features of the human brain have been reliably associated with individual perceptual and cognitive traits (Maguire et al., 2000; Gaser and Schlaug, 2003; Gilaie-Dotan et al., 2011, 2013; Kanai and Rees, 2011), here we show for the first time that individual economic preferences can be predicted from brain structure. The volume of the cortical sheet in the right PPC appears to be predictive of individual risk attitude in the financial decision-making task we used.

The PPC has long been implicated in decision-making processes. In monkeys, the activity of neurons in the PPC encodes the subjective desirability of lotteries, delayed rewards, and social rewards (Platt and Glimcher, 1999; Dorris and Glimcher, 2004; Sugrue et al., 2004; Yang and Shadlen, 2007; Klein et al., 2008; Louie and Glimcher, 2010). In humans, BOLD activation in a similar region in both hemispheres has correlated with the level of uncertainty in a lottery (Huettel et al., 2005), and activity in this region in the left hemisphere has correlated with individual risk preferences (Huettel et al., 2006). Recent meta-studies have also shown that activity in the PPC (although perhaps in more medial regions) correlates with subjective value, and identified this area of the human brain as decisionrelated (Bartra et al., 2013; Clithero and Rangel, 2013). The particular region identified in our study overlaps with an area previously labeled as IPS1 (Schluppeck et al., 2005). IPS1 contains a topographic spatial map of delayed saccades (Schluppeck et al., 2005) or attended locations (Silver et al., 2005), and has been suggested as a possible homolog of the lateral intraparietal (LIP) area in monkeys. LIP is the area that was mostly studied in electrophysiological studies that implicated the PPC in decision processes (Platt and Glimcher, 1999). This is because in these studies monkeys used saccades to indicate their choices. It is likely, however, that other regions in the PPC would show similar properties were other effectors used (Kable and Glimcher, 2009). Moreover, human studies have documented little, if any, effector selectivity in PPC (Hagler et al., 2007; Levy et al., 2007), such that activation in the homologues of IPS1 would be expected even for the finger presses used to respond to our stimuli. Thus, our data extend the functional findings regarding the PPC into a more cost-effective policy-relevant domain by showing that a purely structural feature of this brain region describes risk preference: an anatomical biomarker for financial risk-attitude that could be easily measured in simple and widely available medical brain scans.

If PPC cortical volume indeed reflects risk preferences, then both should exhibit similar degrees of stability and flexibility. This is indeed the case. Preferences are typically taken as a primitive in economic analysis and assumed to be relatively stationary in adult healthy individuals. For example, students tested in an incentivized task similar to ours exhibited stable preferences over a 4-week period (Harrison et al., 2005). Some variations in risk attitudes were observed over a much longer period of time (17 months) in a representative sample of Danes, but the withinsubject variation was much smaller than the between-subject variance (Andersen et al., 2008). Other studies have shown that individual risk preferences can be temporarily influenced by a range of exogenous manipulations, such as weather (Bassi et al., 2013) or metabolic state (Yamada et al., 2013), but the relative ranking of individuals in terms of their risk attitudes did not change (Yamada et al., 2013). Although the literature on the stability of risk attitudes is fairly recent, existing studies sug- 
gest that individual risk attitudes are relatively stable in the short run even though there are individual factors that can influence risk tolerance.

Similar to risk preferences, cortical neuroanatomy is relatively stable over time in healthy midlife adults, yet susceptible to localized and specific short-term (hours to weeks) changes following experimental manipulations (Draganski et al., 2004; Ilg et al., 2008; Sagi et al., 2012). For example, local volume of GM and WM have been shown to change over a period of weeks following motor or visual training (Draganski et al., 2004; Ilg et al., 2008; Scholz et al., 2009; Kühn et al., 2014), and WM changes in hippocampal regions have even been observed following a few hours of perceptual learning in the visual domain (Sagi et al., 2012). Nevertheless, a recent study found that enduring longitudinal cognitive (navigational) changes are associated with enduring changes in hippocampal neuroanatomy, in a longer time scale of up to 4 years (Woollett and Maguire, 2011). Similar to risk preferences, longitudinal intra-individual local changes in neuroanatomy are assumed to be on a smaller scale relative to the existing differences in neuroanatomy across individuals.

Our finding may also be of interest when considering longer time scale perspectives, such as of human development and aging, as well as with regard to illness and other conditions associated with changes in brain structure. Aging is associated with the thinning of various cortical areas, including parietal regions (Salat et al., 2004; Thambisetty et al., 2010), as well as with reduced risk tolerance (Tymula et al., 2013). An intriguing possibility, although one that we could not test in the current study, is that cortical volume may in fact be a better predictor of risk preference than age per se. This biomarker of risk preferences, however, offers an opportunity to unite numerous previously documented associations between risk preferences and a host of variables, such as age, illness, medications, drug abuse, and experience, into a coherent theory of the biological foundations of risk attitudes.

Our result suggests that models of decision-making should relate neuronal volume to risk attitude; that a larger GM volume may allow for a less compressed representation of value (Louie and Glimcher, 2012), and thus greater tolerance for risk. We do not know precisely how GM volume translates to the neural level. It is possible that volume differences reflect synaptogenesis and dendritic arborization (Kanai and Rees, 2011), but to-date there is no clear evidence of correlation between GM volume measured by VBM and any histological measure, including neuronal density (Eriksson et al., 2009). However, it is possible that (at least under some conditions) more volume entails higher computational capacity. If this turns out to be the case, it will suggest that our empirical observation is consistent with a purely theoretical derivation by Woodford (2012), demonstrating that increased risk tolerance would be expected as computational capacity increases.

Finally, we cannot stress enough three critical points: first, our findings were made in a specific population of participants, young university students living in big cities in the northeastern part of the United States of America, typical to studies of experimental psychology, neuroimaging, and economics. Therefore, one cannot conclude from our findings that cortical volume in the right PPC predicts risk attitude in all humans without completing further studies in other populations. Second, our findings do not imply a fixed deterministic relation between genetics and risk attitude. It may be the case that the environment determines cortical volume in this area or even that one's behavior with regard to risky options shapes this brain area. Third, our data so far are silent about causal relations. We cannot yet say that gray matter volume in the PPC causes a greater tolerance for risk, or the higher financial returns often associated with that preference. Our results do, however, relate brain morphology to an individual decision-making trait for the first time and suggest the existence of an anatomical biomarker for financial risk-attitude that could be easily extracted from abundance of existing medical brain scans.

\section{References}

Andersen S, Harrison GW, Lau MI, Rutstroem EE (2008) Lost in state space: are preferences stable? Int Econ Rev 49:1091-1112. CrossRef

Ashburner J (2007) A fast diffeomorphic image registration algorithm. Neuroimage 38:95-113. CrossRef Medline

Ashburner J, Friston KJ (2000) Voxel-based morphometry: the methods. Neuroimage 11:805-821. CrossRef Medline

Bartra O, McGuire JT, Kable JW (2013) The valuation system: a coordinatebased meta-analysis of BOLD fMRI experiments examining neural correlates of subjective value. Neuroimage 76:412-427. CrossRef Medline

Bassi A, Colacito R, Fulghieri P (2013) 'O sole mio: an experimental analysis of weather and risk attitudes in financial decisions. Rev Financ Stud 26: 1824-1852. CrossRef

Bernoulli D (1954) Exposition of a new theory on the measurement of risk. Econometrica 22:23-36. CrossRef

Chib VS, Rangel A, Shimojo S, O’Doherty JP (2009) Evidence for a common representation of decision values for dissimilar goods in human ventromedial prefrontal cortex. J Neurosci 29:12315-12320. CrossRef Medline

Clithero JA, Rangel A (2013) Informatic parcellation of the network involved in the computation of subjective value. Soc Cogn Affect Neurosci. Advance online publication. Retrieved Aug. 21, 2013. CrossRef Medline

Dorris MC, Glimcher PW (2004) Activity in posterior parietal cortex is correlated with the relative subjective desirability of action. Neuron 44:365378. CrossRef Medline

Draganski B, Gaser C, Busch V, Schuierer G, Bogdahn U, May A (2004) Neuroplasticity: changes in grey matter induced by training. Nature 427 : 311-312. CrossRef Medline

Eriksson SH, Free SL, Thom M, Symms MR, Martinian L, Duncan JS, Sisodiya SM (2009) Quantitative grey matter histological measures do not correlate with grey matter probability values from in vivo MRI in the temporal lobe. J Neurosci Methods 181:111-118. CrossRef Medline

Gaser C, Schlaug G (2003) Gray matter differences between musicians and nonmusicians. Ann N Y Acad Sci 999:514-517. CrossRef Medline

Gilaie-Dotan S, Kanai R, Rees G (2011) Anatomy of human sensory cortices reflects inter-individual variability in time estimation. Front Integr Neurosci 5:76. CrossRef Medline

Gilaie-Dotan S, Kanai R, Bahrami B, Rees G, Saygin AP (2013) Neuroanatomical correlates of biological motion detection. Neuropsychologia 51: 457-463. CrossRef Medline

Gilboa I, Schmeidler D (1989) Maxmin expected utility with non-unique prior. J Math Econ 18:141-153. CrossRef

Hagler DJ Jr, Riecke L, Sereno MI (2007) Parietal and superior frontal visuospatial maps activated by pointing and saccades. Neuroimage 35:15621577. CrossRef Medline

Hare TA, Camerer CF, Rangel A (2009) Self-control in decision-making involves modulation of the vmPFC valuation system. Science 324:646648. CrossRef Medline

Harrison GW, Rutstrom E (2008) Risk aversion in the laboratory. In: Research in experimental economics (Cox JC, Harrison GW, eds), pp 41196. Bingley, UK: Emerald Group Publishing.

Harrison GW, Johnson EI, McInnes MM, Rutstrom EE (2005) Tempora stability of estimates of risk aversion. Appl Financ Econ Lett 1:31-35. CrossRef

Hayasaka S, Phan KL, Liberzon I, Worsley KJ, Nichols TE (2004) Nonstationary cluster-size inference with random field and permutation methods. Neuroimage 22:676-687. CrossRef Medline

Huettel SA, Song AW, McCarthy G (2005) Decisions under uncertainty: probabilistic context influences activation of prefrontal and parietal cortices. J Neurosci 25:3304-3311. CrossRef Medline

Huettel SA, Stowe CJ, Gordon EM, Warner BT, Platt ML (2006) Neural signatures of economic preferences for risk and ambiguity. Neuron 49: 765-775. CrossRef Medline 
Ilg R, Wohlschläger AM, Gaser C, Liebau Y, Dauner R, Wöller A, Zimmer C, Zihl J, Mühlau M (2008) Gray matter increase induced by practice correlates with task-specific activation: a combined functional and morphometric magnetic resonance imaging study. J Neurosci 28:4210-4215. CrossRef Medline

Izuma K, Saito DN, Sadato N (2008) Processing of social and monetary rewards in the human striatum. Neuron 58:284-294. CrossRef Medline

Kable JW, Glimcher PW (2007) The neural correlates of subjective value during intertemporal choice. Nat Neurosci 10:1625-1633. CrossRef Medline

Kable JW, Glimcher PW (2009) The neurobiology of decision: consensus and controversy. Neuron 63:733-745. CrossRef Medline

Kahneman D, Tversky A (1979) Prospect theory: analysis of decision under risk. Econometrica 47:263-291. CrossRef

Kanai R, Rees G (2011) The structural basis of inter-individual differences in human behaviour and cognition. Nat Rev Neurosci 12:231-242. CrossRef Medline

Klein JT, Deaner RO, Platt ML (2008) Neural correlates of social target value in macaque parietal cortex. Curr Biol 18:419-424. CrossRef Medline

Kriegeskorte N, Simmons WK, Bellgowan PS, Baker CI (2009) Circular analysis in systems neuroscience: the dangers of double dipping. Nat Neurosci 12:535-540. CrossRef Medline

Kuhn S, Gleich T, Lorenz RC, Lindenberger U, Gallinat J (2014) Playing Super Mario induces structural brain plasticity: gray matter changes resulting from training with a commercial video game. Mol Psychiatry 19: 265-271. CrossRef Medline

Kuhnen CM, Knutson B (2005) The neural basis of financial risk taking. Neuron 47:763-770. CrossRef Medline

Levy DJ, Glimcher PW (2011) Comparing apples and oranges: using reward-specific and reward-general subjective value representation in the brain. J Neurosci 31:14693-14707. CrossRef Medline

Levy I, Schluppeck D, Heeger DJ, Glimcher PW (2007) Specificity of human cortical areas for reaches and saccades. J Neurosci 27:4687-4696. CrossRef Medline

Levy I, Snell J, Nelson AJ, Rustichini A, Glimcher PW (2010) Neural representation of subjective value under risk and ambiguity. J Neurophysiol 103:1036-1047. CrossRef Medline

Levy I, Rosenberg Belmaker L, Manson K, Tymula A, Glimcher PW (2012) Measuring the subjective value of risky and ambiguous options using experimental economics and functional MRI methods. J Vis Exp 67: e3724. CrossRef Medline

Louie K, Glimcher PW (2010) Separating value from choice: delay discounting activity in the lateral intraparietal area. J Neurosci 30:54985507. CrossRef Medline

Louie K, Glimcher PW (2012) Efficient coding and the neural representation of value. Ann N Y Acad Sci 1251:13-32. CrossRef Medline

Maguire EA, Gadian DG, Johnsrude IS, Good CD, Ashburner J, Frackowiak RS, Frith CD (2000) Navigation-related structural change in the hippocampi of taxi drivers. Proc Natl Acad Sci U S A 97:4398-4403. CrossRef Medline

O’Doherty JP, Deichmann R, Critchley HD, Dolan RJ (2002) Neural responses during anticipation of a primary taste reward. Neuron 33:815826. CrossRef Medline
Plassmann H, O’Doherty J, Rangel A (2007) Orbitofrontal cortex encodes willingness to pay in everyday economic transactions. J Neurosci 27: 9984-9988. CrossRef Medline

Platt ML, Glimcher PW (1999) Neural correlates of decision variables in parietal cortex. Nature 400:233-238. CrossRef Medline

Preuschoff K, Bossaerts P, Quartz SR (2006) Neural differentiation of expected reward and risk in human subcortical structures. Neuron 51:381390. CrossRef Medline

Sagi Y, Tavor I, Hofstetter S, Tzur-Moryosef S, Blumenfeld-Katzir T, Assaf Y (2012) Learning in the fast lane: new insights into neuroplasticity. Neuron 73:1195-1203. CrossRef Medline

Salat DH, Buckner RL, Snyder AZ, Greve DN, Desikan RS, Busa E, Morris JC, Dale AM, Fischl B (2004) Thinning of the cerebral cortex in aging. Cereb Cortex 14:721-730. CrossRef Medline

Schluppeck D, Glimcher P, Heeger DJ (2005) Topographic organization for delayed saccades in human posterior parietal cortex. J Neurophysiol 94: 1372-1384. CrossRef Medline

Scholz J, Klein MC, Behrens TE, Johansen-Berg H (2009) Training induces changes in white-matter architecture. Nat Neurosci 12:1370-1371. CrossRef Medline

Silver MA, Ress D, Heeger DJ (2005) Topographic maps of visual spatial attention in human parietal cortex. J Neurophysiol 94:1358-1371. CrossRef Medline

Sugrue LP, Corrado GS, Newsome WT (2004) Matching behavior and the representation of value in the parietal cortex. Science 304:1782-1787. CrossRef Medline

Thambisetty M, Wan J, Carass A, An Y, Prince JL, Resnick SM (2010) Longitudinal changes in cortical thickness associated with normal aging. Neuroimage 52:1215-1223. CrossRef Medline

Tymula A, Rosenberg Belmaker LA, Roy AK, Ruderman L, Manson K, Glimcher PW, Levy I (2012) Adolescents' risk-taking behavior is driven by tolerance to ambiguity. Proc Natl Acad Sci U S A 109:17135-17140. CrossRef Medline

Tymula A, Rosenberg Belmaker LA, Ruderman L, Glimcher PW, Levy I (2013) Like cognitive function, decision making across the life span shows profound age-related changes. Proc Natl Acad Sci U S A 110: 17143-17148. CrossRef Medline

Von Neumann J, Morgenstern O (1944) Theory of games and economic behavior. Princeton: Princeton UP.

Weber EU, Blais AR, Betz NE (2002) A domain-specific risk-attitude scale: measuring risk perceptions and risk behaviors. J Behav Decis Making 15:263. CrossRef

Woodford M (2012) Prospect theory as efficient perceptual distortion. Am Econ Rev 102:41-46. CrossRef

Woollett K, Maguire EA (2011) Acquiring "the knowledge" of London's layout drives structural brain changes. Curr Biol 21:2109-2114. CrossRef Medline

Yamada H, Tymula A, Louie K, Glimcher PW (2013) Thirst-dependent risk preferences in monkeys identify a primitive form of wealth. Proc Natl Acad Sci U S A 110:15788-15793. CrossRef Medline

Yang T, Shadlen MN (2007) Probabilistic reasoning by neurons. Nature 447:1075-1080. CrossRef Medline 